\title{
PENGEMBANGAN JARINGAN HOTSPOT MENGGUNAKAN MIKROTIK ROUTERBOARD RB951Ui- 2HnD PADA SMKN 2 SELONG
}

\author{
Ahmad Subki ${ }^{1}$, Juhartini ${ }^{2}$, Muh. Nasirudin Karim ${ }^{3}$ \\ Universitas Teknologi Mataram ${ }^{1,2,3}$ \\ ahmad.subki1992@gmail.com
}

\begin{abstract}
Abstrak
Teknologi informasi sudah merambah ke berbagai bidang termasuk pendidikan, semakin berkembang teknologi informasi sekarang ini, maka kebutuhan akan informasi saat ini semakin meningkat pula. Saat ini setiap orang membutuhkan informasi dalam waktu yang cepat, singkat dan akurat oleh karena itu dibutuhkan sarana yang dapat mendukung teknologi informasi tersebut, salah satunya adalah koneksi internet. Pembuatan Hotspot ada beberapa hal yang sangat diutamakan, seperti pembagian bandwith, pembagian user serta kemudahan-kemudahan lain yang bisa meningkatkan kinerja dari SMKN 2 Selong. Kata kunci: Jaringan, Hotspot, MikroTik.
\end{abstract}

\section{Latar Belakang}

Teknologi informasi sudah merambah ke berbagai bidang termasuk pendidikan, semakin berkembang teknologi informasi sekarang ini, maka kebutuhan akan informasi saat ini semakin meningkat pula. Saat ini setiap orang membutuhkan informasi dalam waktu yang cepat, singkat dan akurat oleh karena itu dibutuhkan sarana yang dapat mendukung teknologi informasi tersebut, salah satunya adalah koneksi internet.

$$
\text { Untuk membangun atau }
$$

mengembangkan jaringan internet tidak mudah, karena kenyataanya perangkat untuk mengembangkan sebuah jaringan internet pada saat ini tergolong mahal dan tidak hanya itu pemasangan jaringan internet juga membutuhkan keahlian khusus untuk bisa melakukanya dengan benar sehingga permasalahan seperti yang ada bisa diselesaikan.

Tujuan dari pengembangan jaringan Hotspot pada SMKN 2 Selong yaitu untuk memberikan pengetahuan yang lebih jauh lagi akan fungsi dan kegunaan internet kepada semua siswa dan mencakup tentang hal-hal berikut yaitu Menghasilkan Jaringan Hotspot menggunakan MikroTik RouterBoard RB951Ui-2HnD SMKN 2 Selong.

\section{Kajian Pustaka}

Jaringan komputer adalah sebuah sistem yang terdiri atas komputer-komputer yang didesain untuk dapat berbagi sumber daya (printer, CPU), berkomunikasi (surel, pesan instan), dan dapat mengakses informasi (peramban web). Tujuan dari jaringan komputer adalah agar dapat mencapai tujuannya, setiap bagian dari jaringan komputer dapat meminta dan memberikan layanan (service). Pihak yang meminta/menerima layanan disebut klien (client) dan yang memberikan/mengirim layanan disebut peladen (server). Desain ini disebut dengan sistem client-server, dan digunakan pada hampir seluruh aplikasi jaringan komputer (Yudianto, 2014).

Menurut (Wongkar, Sinsuw, \& Xaverius, 2015), bahwa Jaringan komputer adalah "interkoneksi" antara 2 komputer autonomous atau lebih, yang terhubung dengan media transmisi kabel atau tanpa kabel (wireless). Autonomous adalah apabila sebuah komputer tidak melakukan kontrol terhadap komputer lain dengan akses penuh, sehingga dapat membuat komputer lain, restart, shutdows, kehilangan file atau kerusakan sistem.

Topologi jaringan komputer adalah suatu cara menghubungkan komputer yang satu dengan komputer lainnya sehingga membentuk jaringan. Dalam suatu jaringan komputer jenis topologi yang dipilih akan mempengaruhi kecepatan komunikasi. Topologi jaringan yang biasa digunakan ada tiga jenis (Sarmidi, 2016), yakni:

a. Topologi Bus merupakan jenis 'topologi yang memiliki mode paling sederhana, terdiri dari sebuah kabel trunk (backbone atau segment) yang menghubungkan semua komputer yang

Pengembangan Jaringan Hotspot Menggunakan Mikrotik Routerboard Rb951ui-2HnD Pada Smkn 2 Selong 
tergabung dalam sebuah jaringan dalam sebuah jalur.

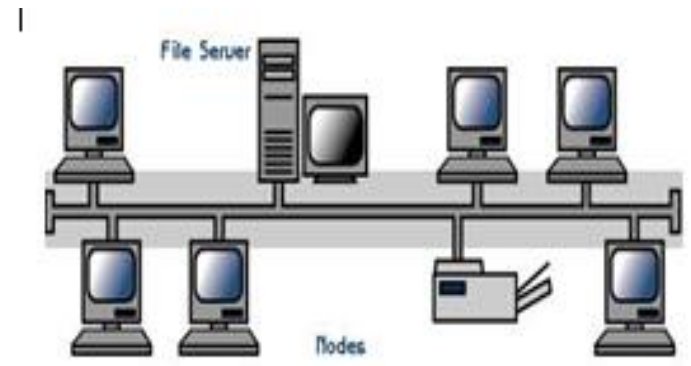

Figure 1. Topologi Bus

b. Topologi Star, dalam topologi Star, komputerkomputer terhubung melalui kabel ke sebuah komponen secara terpusat yang disebut dengan hub. Sinyal dikirim ke semua komputer dari komputer pengirim melalui hub ke semua komputer yang terhubung dengan hub. Jaringan star menawarkan mekanisme manajeman dan resource secara terpusat. Tetapi karena masing-masing komputer dihubungkan ke sebuah device secara terpusat, jika device ini mengalami kerusakan maka jaringan akan mengalami down (komputer komputer yang terhubung dengan hub yang rusak tidak dapat saling berkomunikasi).

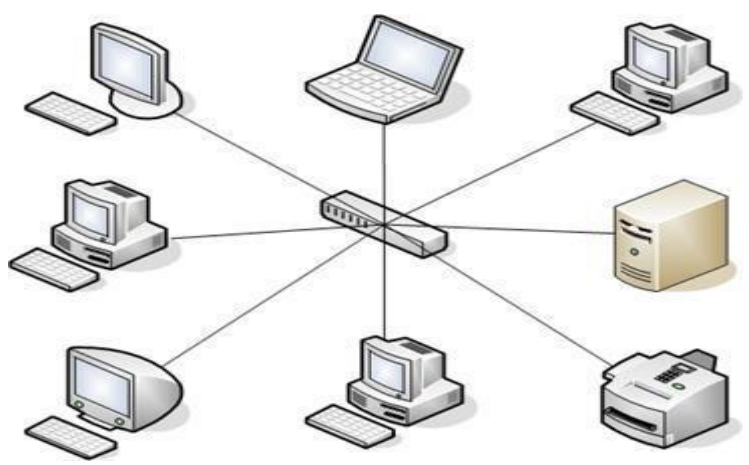

Figure 2. Topologi Star

c. Topologi Ring menghubungkan komputer dengan cara membentuk sebuah lingkaran kabel. Sinyal berjalan mengelilingi lingkaran dengan satu arah dan sinyal tersebut dilewatkan melalui masing-masing komputer. Tidak seperti topologi Bus, masing-masing komputer bertindak seperti sebuah repeater untuk memperkuat sinyal dan mengirimkanya ke komputer lain. Karena sinyal dilewatkan melalui masing-masing komputer, kerusakan dari satu komputer dapat mempengaruhi seluruh jaringan.

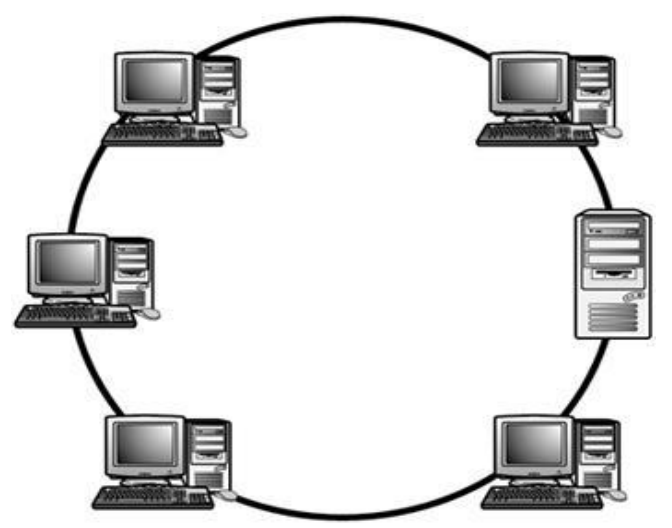

Figure 3. Topologi Ring

d. Topologi Mesh, Topologi Mesh adalah suatu topologi yang memang didisain untuk memiliki tingkat restorasi dengan berbagai alternatif rute atau penjaluran yang biasanya disiapkan dengan dukungan perangkat lunak atau software. Topologi jaringan mesh ini menerapkan hubungan antar sentral secara penuh.

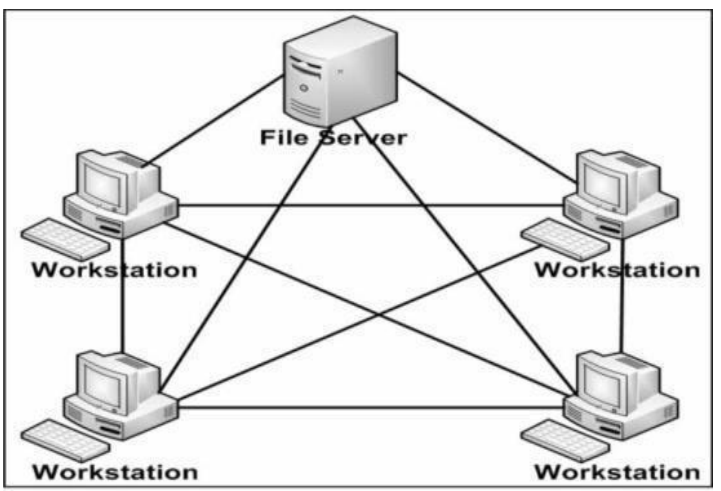

Figure 4. Topologi Mesh

Protokol Jaringan yang banyak digunakan saat ini adalah protokol TCP/IP (Transmission Control Protocol/Internet Protocol) yang merupakan sekelompok protokol yang mengatur komunikasi data komputer di internet. Komputer-komputer yang terhubumg ke internet berkomunikasi dengan TCP/IP, karena menggunakan bahasa yang sama perbedaan jenis

Pengembangan Jaringan Hotspot Menggunakan Mikrotik Routerboard Rb951ui-2HnD Pada Smkn 2 Selong 
komputer dan sistem operasi tidak menjadi masalah. Jadi jika sebuah komputer menggunakan protocol TCP/IP dan terhubung langsung ke internet, maka komputer tersebut dapat berhubungan dengan komputer manapun yang terhubung dengan internet.

Alamat IP digunakan untuk metode pengalamatan layer Internet. Saat ini banyak digunakan IP versi 4, menggunakan 32 bit biner dan sistem bilangan yang digunakan adalah sistem bilangan decimal.

Sedangkan alamat MAC (Media Acces Control) merupakan metode pengalamatan di layer network acces. Dikenal pula dengan istilah hardware address. Menggunakan 48 bit biner atau 12 digit hexadesimal.

Tabel 1. Metode Pengalamatan TCP/IP

\begin{tabular}{|l|l|}
\hline $\begin{array}{l}\text { Arsitektur } \\
\text { TCP/IP }\end{array}$ & \multicolumn{2}{|l|}{ Metode Pengalamatan } \\
\hline $\begin{array}{l}\text { Process } \\
\text { Aplication }\end{array}$ & $\begin{array}{l}\text { Nama Host (Hosted } \\
\text { Name) }\end{array}$ \\
\hline Host to Host & $\begin{array}{l}\text { Nomor Port } \\
\text { Number) }\end{array}$ \\
\hline Internet & Alamat IP (IP Address) \\
\hline Network Access & Hardware Address \\
\hline
\end{tabular}

Alamat IP menggunakan sistem bilangan desimal, berikut contoh alamat IP:

10.1.1.5

172.16.10.10

192.168.10.100

\section{Analisis Sistem}

Setelah menganalisa beberapa permasalahan tersebut maka perlu dikembangkan Jaringan Hotspot menggunakan MikroTik RB951 pada SMK Negeri 2 Selong dan hal ini bertujuan agar siswa maupun guru pada SMK Negeri 2 Selong bisa menggunakan jaringan internet sesuai dengan jalur yang sudah ditentukan. Disini menggunakan router MikroTik RB951 sebagai media Hotspot yang dimana para user dari masing- masing komputer seperti diruang ruang guru dan ruang belajar dapat mengakses jaringan HotSpot sesuai dengan jalur yang sudah ditentukan.

\section{a. Peranjangan Jaringan}

\section{Skema Lama}

SMK Negeri 2 Selong dalam skema lama komputer sudah memiliki koneksi internet yang saling terhubung antara satu komputer dengan komputer yang lain akan tetapi belum tersedianya jalur-jalur

Pengembangan Jaringan Hotspot Menggunakan Mikrotik Routerboard Rb951ui-2HnD

\section{Skema Baru}

khusus yang digunakan para siswa dan guru untuk mengakses jaringan internet yang sudah ada pada SMK Negeri 2 Selong, seperti figure 5.

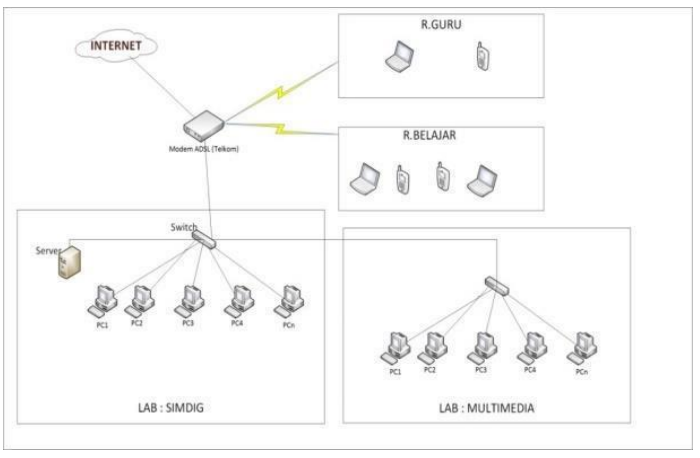

Figure 5. Sekema Jaringan Lama

Dalam pengembangan jaringan internet menggunakan router MikroTik $R B 951$ dibutuhkan beberapa perangkat yang saling terhubung antara satu dengan yang lain, disini menggunakan 1 unit router Mikrotik, Modem ADSL/ISP dan Switch dimana ISP akan menghubungkan ke Router MikroTik, maka Router MikroTik akan memancarkan sinyal Wireless yang dipancarkan oleh Router MikroTik dapat diterima oleh client yang terhubung ke jaringan, seperti figure 6 .

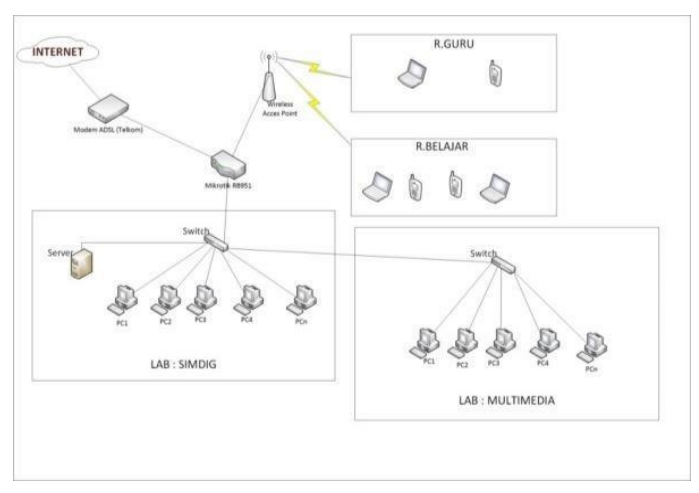

Figure 6. Sekema Jaringan Baru

Dalam pembuatan Penelitian ini akan dirancang sebuah jaringan dengan menggunakan 41 client 20 di dalam Lab Simdig dan 24 di dalam lab Multimedia 1 server yaitu 4 client berada diruang guru 2 client berada diruang guru menggunakan Handphone, 7 client berada di ruang belajar 
sekolah menggunakan Handphone dengan menggunakan Topologi Star.

Topologi Star merupakan bentuk topologi jaringan yang berupa konverensi dari node tengah ke setiap node atau pengguna. Topologi jaringan star termasuk topologi jaringan dengan biaya menengah dan memiliki kelebihan yaitu cukup mudah untuk mengubah dan menambah komputer ke dalam jaringan yang menggunakan topologi star tanpa mengganggu aktvitas jaringan yang sedang berlangsung apabila satu komputer yang mengalami kerusakan dalam jaringan maka komputer tersebut tidak akan membuat mati seluruh jaringan star, dapat menggunakan beberapa tipe kabel di dalam jaringan yang sama dengan hub yang dapat mengakomodasi tipe kabel yang berbeda.

Kerusakan pada satu saluran hanya akan mempengaruhi jaringan pada saluran tersebut dan station yang terpaut. Penambahan dan pengurangan station dapat dilakukan dengan mudah tetapi topologi star memiliki kekurang pula diantarannya : Memiliki satu titik kesalahan, terletak pada hub. Jika hub pusat mengalami kegagalan, maka seluruh jaringan akan gagal untuk beroperasi. Membutuhkan lebih banyak kabel karena semua kabel jaringan harus ditarik ke satu central point, jadi lebih banyak membutuhkan lebih banyak kabel daripada topologi jaringan yang lain. Jumlah terminal terbatas, tergantung dari port yang ada pada hub.

Lalu lintas data yang padat dapat menyebabkan jaringan bekerja lebih lambat, topologi star yang ada pada pada SMK Negeri 2 Selong terlihat didalam Lab komputer dimana memiliki pusat internet berada pada hub dimana terlihat pada figure 7 .

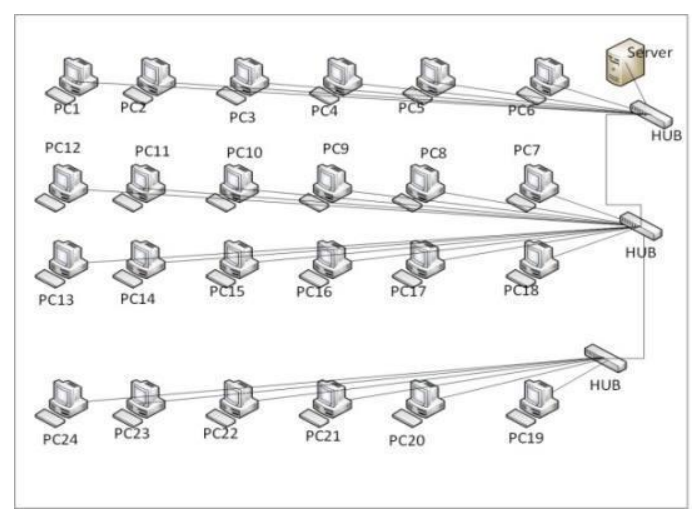

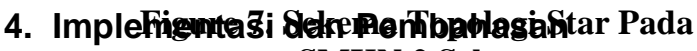

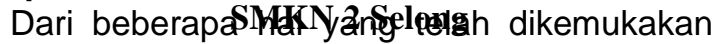
sebelumnya, dalam penelitian ini mencantumkan beberapa batasan masalah yang diantaranya yaitu:

1. Perancangan Skema Jaringan menggunakan Visio 2013

2. Konfigurasi jaringan menggunakan Winbox 3.4

3. Konfigurasi rancangan jaringan manajemen bandwith dan user

4. Konfigurasi situs yang diblok yaitu youtube

5. Mengimplementasikan rancangan jaringan wireless pada SMK Negeri 2 Selong

Diantara yang akan dipaparkan adalah bagian dari alat-alat untuk membuat jaringan Local Area Network (LAN) dan Metropolitan Area Network (MAN) langkah-langkahnya secara sesederhana mungkin yaitu mulai dari awal sampai dengan keseluruhanya dan sistem operasi beserta IP yang digunakan pada jaringan tersebut.

Dalam pengembangan jaringan internet menggunakan router MikroTik RB951 dibutuhkan beberapa perangkat yang saling terhubung antara satu dengan yang lain, disini menggunakan 1 unit router Mikrotik, Modem ADSL/ISP dan Switch dimana ISP akan menghubungkan ke Router MikroTik, maka Router MikroTik akan memancarkan sinyal Wireless yang dipancarkan oleh Router MikroTik dapat diterima oleh client yang terhubung ke jaringan, seperti figure 8 


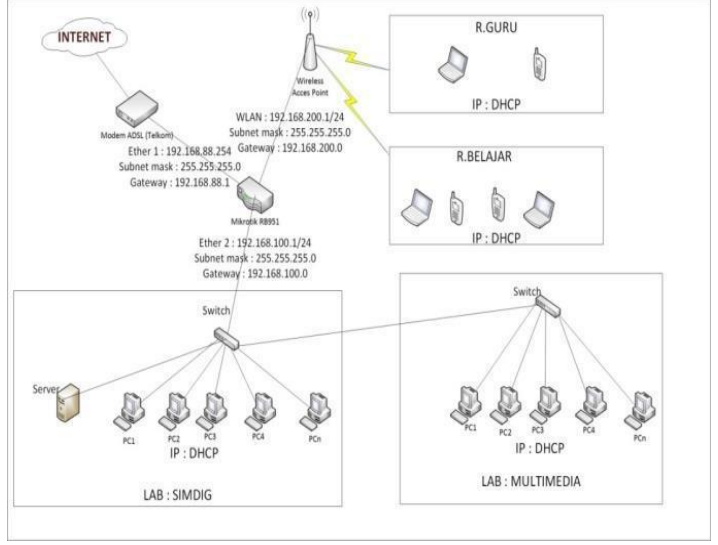

Figure 8. Sekama Rancangan Jaringan

\section{Konfigurasi Jaringan Internet}

1. Pastikan komputer atau Laptop sudah memiliki koneksi internet

2. Selanjutnya akan dibawa kehalaman winbox apa bila sudah memilih MAC Addres dari router MikroTik yang ingin di konfigurasi

3. Selanjutnya mengkonfigurasi jaringan yang sudah dirancang sebelumnya, yaitu mulai dengan konfigurasi untuk $L A N$ maupun Hotspotnya dengan memberi nama masingmasing Ether 1 sebagai publik yaitu dimana Ether 1 ini mendapatkan internet dari modem ADSL/ ISP yang sudah disiapkan tadi dengan cara pilih interface lalu rubah namanya yang awalnya Ether 1 menjadi Ether 1 publik supaya cepat dikonfigurasi dan tidak membingungkan.

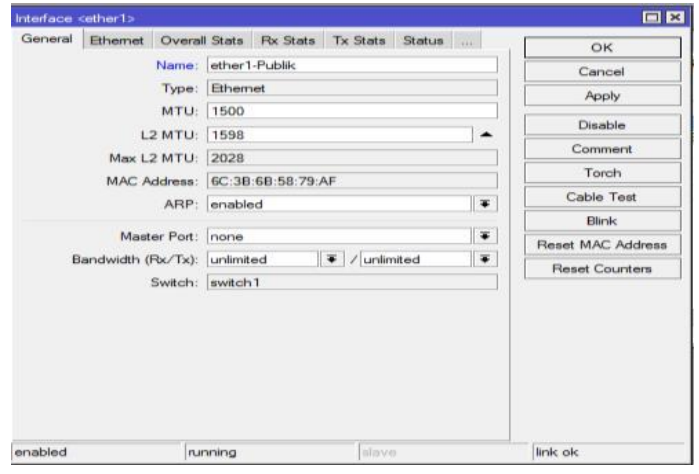

Figure 9. Pengaturan Awal

4. Setelah ether2 kita rubah menjadi ether2lokal selanjutnya merubah nama dan mengaktifkan virtul WLAN sebagai jaringan luar atau Hotspot dengan cara yang sama yaitu Interface, klik 2 kali di WLAN selanjutnya aktifkan WLAN. Hotspot yang akan dipancarkan ke jaringan luar supaya para guru dan siswa bisa mengakses jaringan sesuai yang akan kita buat nanti selanjutnya Apply dan ok dimana tampilannya seperti pada figure 10.

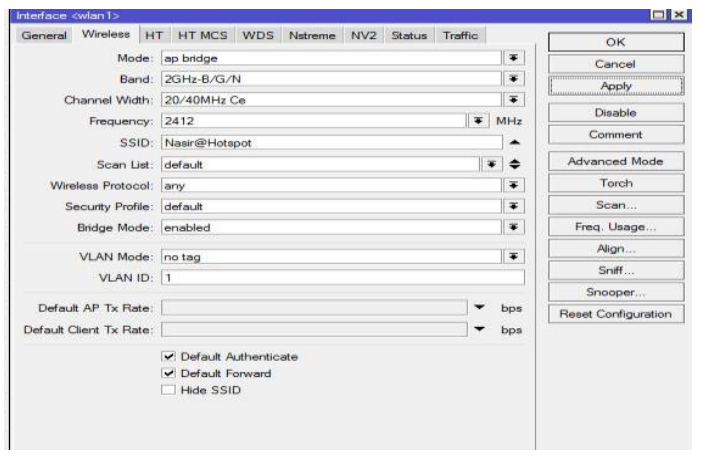

Figure 10. Pengaturan Akses Jaringan

5. Selanjutnya memberikan alamat ip Address pada ether2-lokal atau $L A N$ dan fiktur WLAN yang sudah kita buat pada menu interface dalam memasukan ip address $L A N$ dan WLAN ini melalui Ip terus pilih Address dan masukan ip addres lokal 192.168.100.1/24 network 192.168.100.0 interface Ether2-lokal lalu Apply dan ok, ip address WLAN 192.168.200.1/24Network 192.168.200.0 interface pilin WLAN

selanjutnnya pilih Applay dan ok seperti figure 11 berikut.

\begin{tabular}{|c|c|c|c|}
\hline Address & $0.1 / 24>$ & & $\square$ \\
\hline Address: & $192.168 .100 .1 / 24$ & & OK \\
\hline Network: & 192.168 .100 .0 & $\Delta$ & Cancel \\
\hline Interface: & ether2tokal & $\mp$ & Apply \\
\hline
\end{tabular}

Figure 11. Masukan Alamat IP LAN

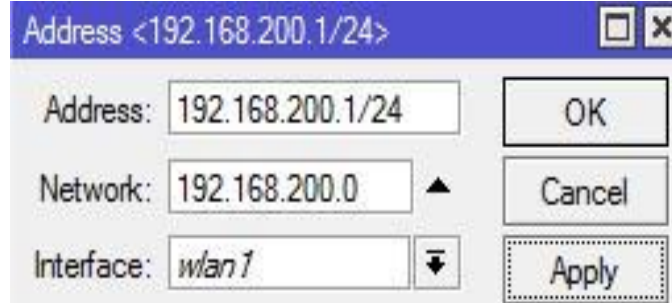

Pengembangan Jaringan Hotspot Menggunakan Mikrotik Routerboard Rb951ui-2HnD Pada Smkn 2 Selong 
Figure 12. Masukan Alamat IP WLAN

6. Selanjutnya masukan $D H C P$ Client yaitu diamana hanya merubah di Default Route Distance : 0 dirubah menjadi Default Route Distance : 1 selanjutnya klik Apply dan ok seperti gambar 4.12 dan pastikan statusnya Bound setelah di ok dimana seperti figure 13.

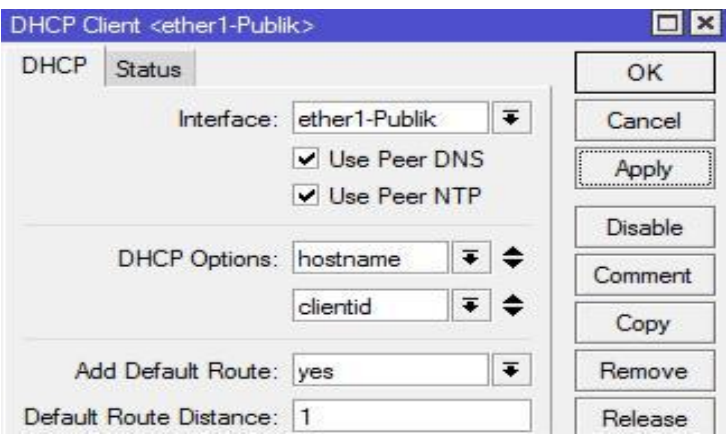

Figure 13. Masukan DHCP

\section{DHCP Client}

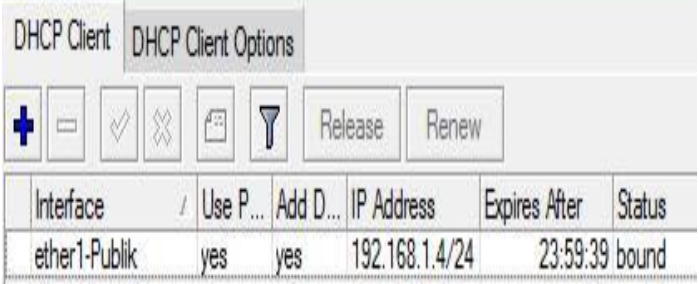

Figure 14. Status DHCP Client

7. Selanjutnya menyeting atau memasukan DNS Domain Name System dimana DNS akan menympan informasi nama atau host domain dalam bentuk basis data yang tersebar didalam jaringan komputer, adapun langkahnya menggunakan Ip dan pilih DNS didalam DNS ini bisa kita gunakan melalui Gateway Ip ISP akan tetapi disini menggunakan DNS Google untuk DNS server yaitu 8.8.8.8 / 8.8.4.4 selanjutnya centang Allow Remote Requests lalu apply dan ok dimana seperti gambar 14 .

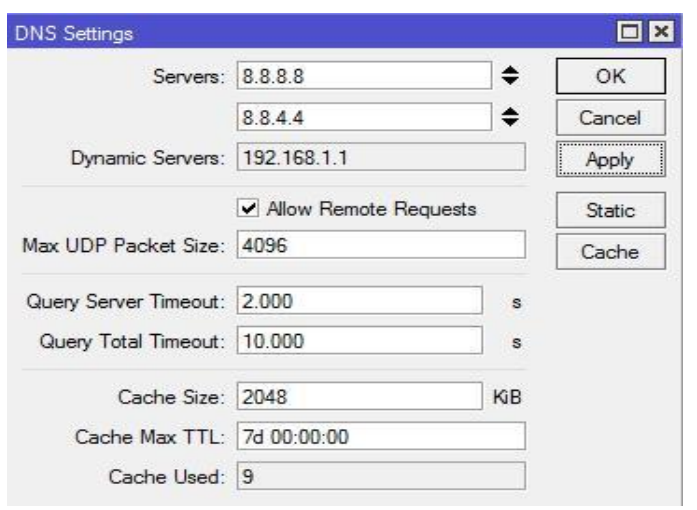

Figure 15. DNS server

8. Setelah menyeting DNS selanjutnya yang perlu diseting lagi yaitu NAT rule. Pada jaringan komputer, proses Network Address Translation (NAT) adalah proses penulisan ulang (masquerade) pada alamat IP asal (source) dan atau alamat IP tujuan (destination), setelah melalui router atau firewall. NAT digunakan pada jaringan dengan workstation yang menggunakan $I P$ Private supaya dapat terkoneksi ke Internet dengan menggunakan satu atau lebih IP Public, pastikan NIC mana yang terkoneksi ke internet dan yang terkoneksi ke LAN disini digunakan Ether1-publik yang terkoneksi internet seperti gambar 4.15 dan pastikan chainnya yaitu srcnat dan action : masquerade setelah itu pilih apply dan oke, seperti figure 16 .

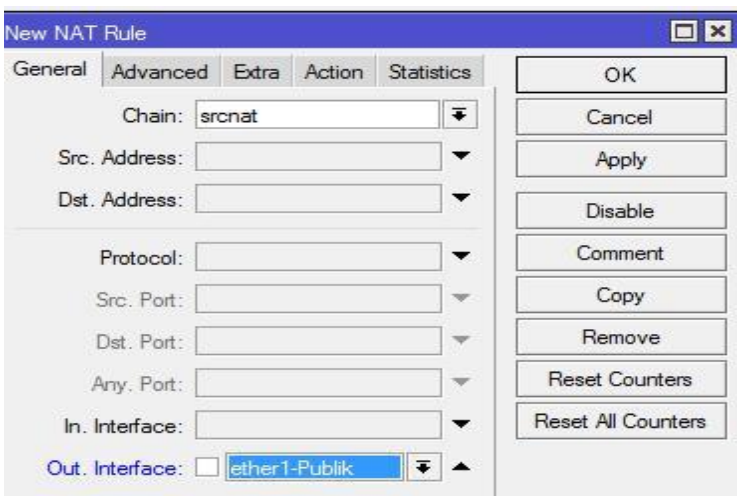

Figure 16. NAT Rule (General)

Pengembangan Jaringan Hotspot Menggunakan Mikrotik Routerboard Rb951ui-2HnD Pada Smkn 2 Selong 


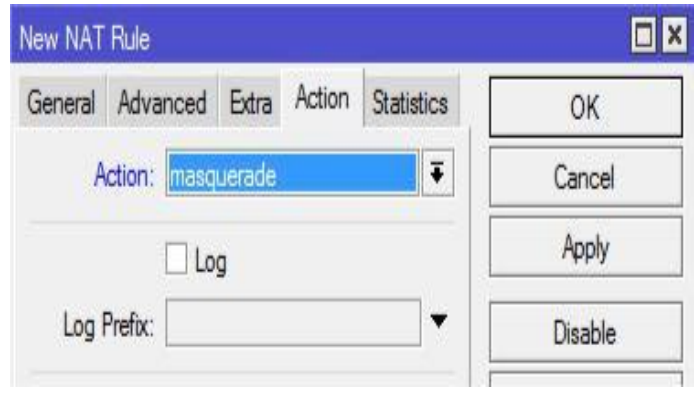

Figure 17. NAT Rule (Action)

9. Setelah penyetingannya selesai sebelum melanjutkan penyetingan atau konfigurasi ke tahap selanjutnya terlebih dahulu tes koneksi internet atau ping untuk $L A N$ yang sudah di seting tadi dengan cara masukan Ip Lan 192.168.100.2subnetmask 255.255.255.248Gateway 192.168.100.1

Pilih ok seperti figure 18 \& pilih New Terminal pada menu WinBox dan tulis Ping google.com lalu enter dan hasilnya terlihat jika berhasil seperti figure 19 .

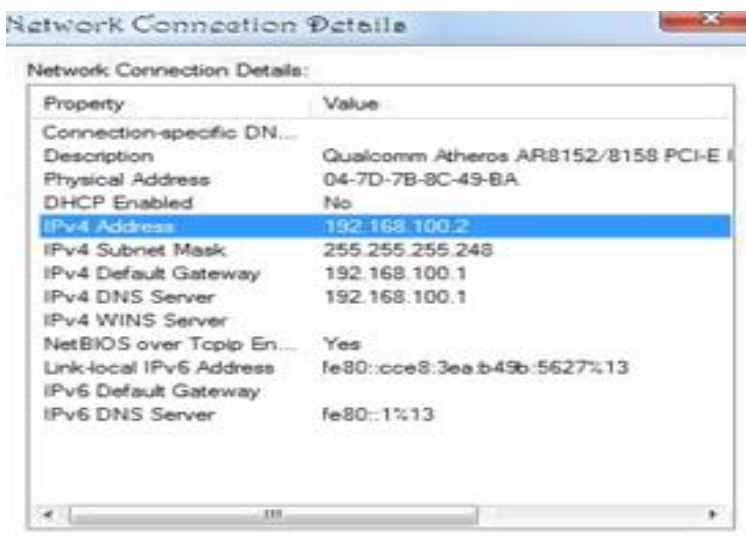

Figure 18. IP Addres untuk LAN

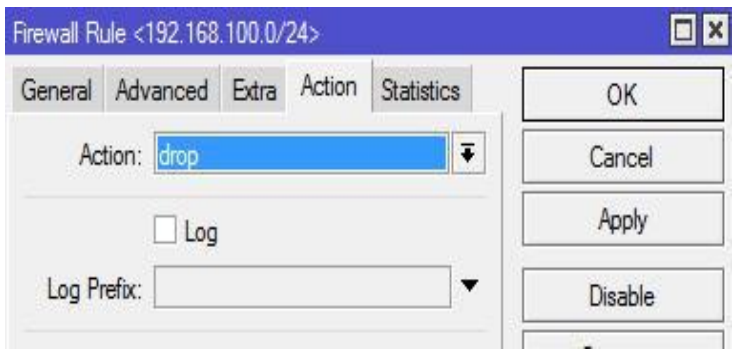

Figure 19. Proses Ping Google

10. Setelah tes koneksi berhasil untuk jaringan LAN selanjutnya memblok situs yang sudah di cantumkan pada batasan masalah yaitu memblok situs Youtube.com menggunakan 7

Pengembangan Jaringan Hotspot Menggunakan Mikrotik Routerboard Rb951ui-2HnD Pada Smkn 2 Selong
Layar protocol dengan memilih tanda add pada ujung kiri seteleh itu akan dibawa pada kotak pemblokiran isikan dengan nama : Streaming dengan lamat situs youtube yaitu ^.+(youtube.com). ${ }^{*}$ setelah semuanya diisi pilih langsung apply dan oke, dimana terlihat seperti figure 20 .

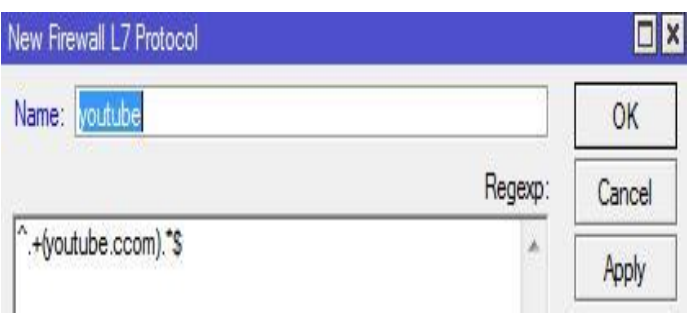

Figure 20. Proses Pemblokiran Situs Youtube.com

Selajutnya aktifkan penyetingan pemblokiran yang sudah dibuat tadi di New Firawell rule dengan pilih general chain : forward pilih src Addres 192.168.100.0/24 dan dimenu advance pilih Layar 7 protokol : streaming nama dari blokiran yang sudah dibuat tadi seperti gambar 4.20 selanjutnya dimenu Action : Drop pilih apply dan ok seperti figure 21 .

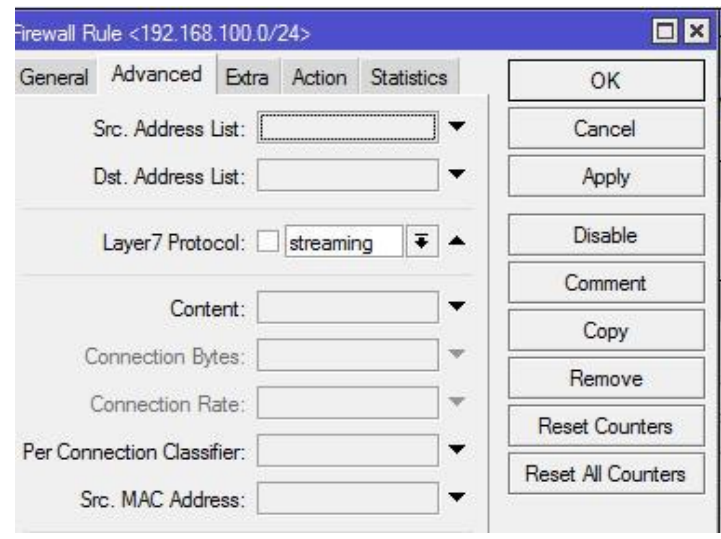

Figure 21. Proses Pengaktifkan Nama Situs yang di Blok 


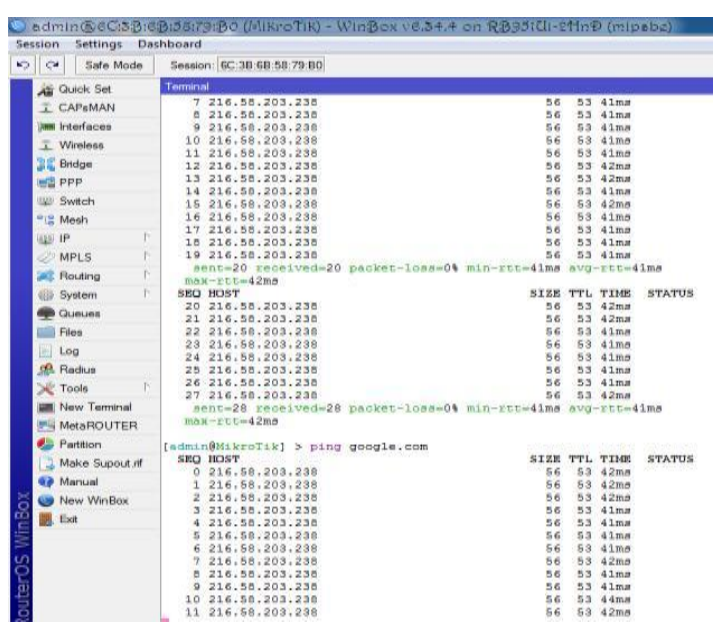

Figure 22.21 Proses Pengaktifkan Viktur Blok di Menu Action

11. Ketika proses pemblokiran situs sudah selesai dilakukan sebelum melanjutkan ketahapan selanjutnya pastikan pemblokiran situs berhasil dimana akan ditest di akhir nanti, selanjutnya membuat Hotspot untuk jaringan diluar Lab dimana nanti akan diakses oleh para guru dan siswa-siswi yang ada pada SMK Negeri 2 Selong adapun langkahlangkahnya yaitu dimenu Hotspot setup lalu pilih Wlan sebagai Wirelass untuk memancarkan sinyal keluar dengan address network 192.168.200.1/24 selanjutnya dengan Address pool of network 192.168.200.2 192.168.200.254 ip address of SMTP Server 0.0.0.0 Dns Server 8.8.8.8 8.8.4.4 Dns Name disini dikosongkan kemudian membuat user dan pasword admin proses pembuatan Hotspot selsai lalu ok seperti terlihat pada gambar berikut ini :

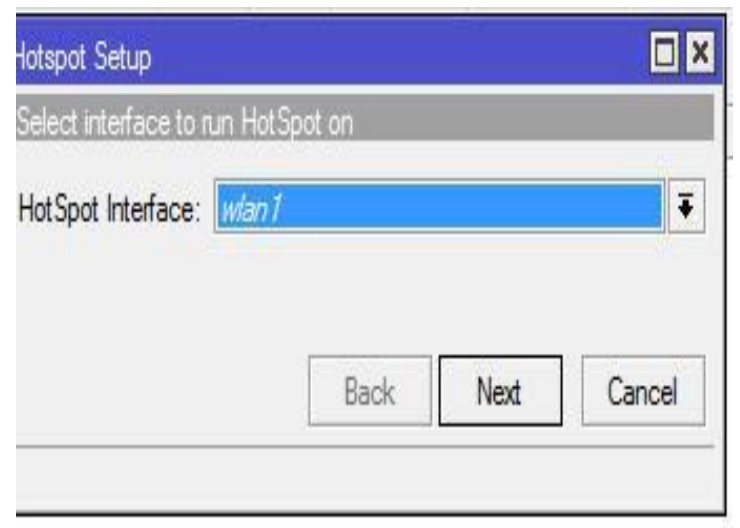

Figure 23. Proses Pengaktifkan Viktur Wlan

12. Selanjutnya pembuatan user bagi guru dan siswa dimenu user profil dan pembuatan Pengembangan Jaringan Hotspot Menggunakan Mikrotik Routerboard Rb951ui-2HnD Pada Smkn 2 Selong password setiap user dimenu user sesuai yang sudah ditentukan seperti gambar 23 sebelumnya dan pembagian bandwith dimana guru mendapatkan unlimited sedangkan untuk siswa $256 \mathrm{k}$.

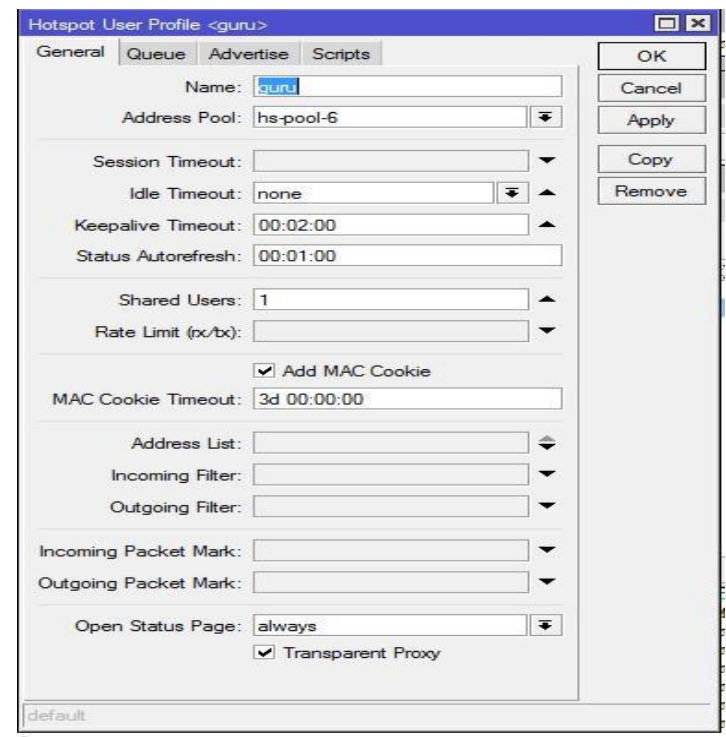

Figure 24. Proses Pembuatan User Guru

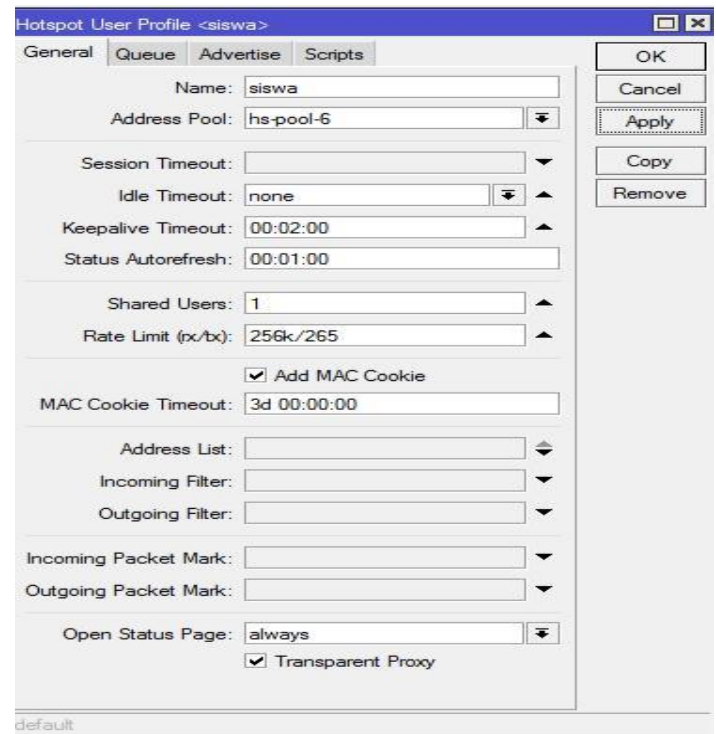

Figure 25. Proses Pembuatan User Siswa

Proses pembutan Hotspot sudah selesai selanjutnya melakukan koneksi internet melalui client yang sudah dibuat tadi dimana guru dan siswa bisa mengakses internet melaui SmartPhone maupun laptop seperti figure 26 . 


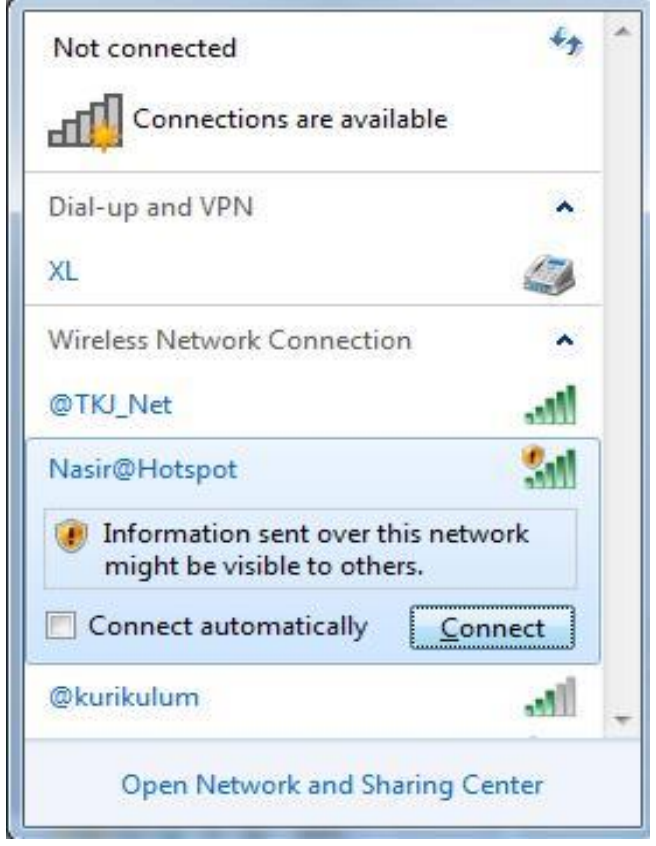

Figure 26. Proses Koneksi Client

mengakses DNS Name atau alamat IP Hotspot disini menggunakan IP Hotspot yaitu 192.168.200.1

\section{$\mathbb{E}$ internet hotspot $>\log$ in $\quad$ t}

\subsubsection{1/login?dst=http\%3A\%2}

Figure 27. Proses Pemanggilan IP Hotspot

Selanjutnya melakukan login atau memasukan user dan password yang sudah dibuat atau didaftarkan dimana seperti figure 28 .

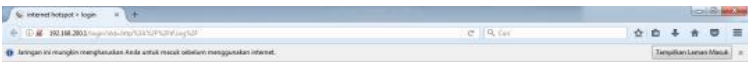

\section{Penutup}

Dari hasil penelitian yang sudah dikemukakan dapat disimpulan sebagai berikut yaitu :

a. Jaringan Hotspot atau Metropolitan Area Network dibangun menggunakan beberapa perangkat yaitu seperti router Mikrotik RB951, switch, modem, cable UTP, konektor $R J-45$, cable tester dan crimping tool.

b. Pada topologi yang digunakan di dalam membangun jaringan Hotspot ini adalah Topologi Bintang (Star Topology).

c. Router Mikrotik RB951 ini tidak hanya digunakan pada jaringan Metropolitan Area Network (MAN) atau Hotspot sebagai pembagian bandwith dan penyebaran sinyal, akan tetapi bisa dijadikan sebagi Local Area Network yang bisa di akses melalui komputer/laptop yang sudah memiliki LAN Card.

\section{Daftar Pustaka}

[1] Sarmidi. (2016). Simulasi Alat Bantu Pembelajaran Topologi Jaringan Secara Visual Simulation. Technoper, 1, 32-38.

[2] Wongkar, S., Sinsuw, A., \& Xaverius, N. (2015). Analisa Implementasi Jaringan Internet Dengan Menggabungkan Jaringan LAN Dan WLAN Di Desa Kawangkoan Bawah Wilayah Amurang II. E-Journal Teknik Elektro Dan Komputer, 4(6), 62-68. https://doi.org/10.1145/1964921.1964982

[3] Yudianto, M. J. N. (2014). Jaringan Komputer dan Pengertiannya. Ilmukomputer.Com, 1$10 . \quad$ Retrieved from http://www.unej.ac.id/files/pdf2/llmukomputer-Jaringan-Komputer-DanPengertiannya.pdf

Figure 28. Proses Login Proses login berhasil

Pengembangan Jaringan Hotspot Menggunakan Mikrotik Routerboard Rb951ui-2HnD Pada Smkn 2 Selong 